\title{
Efficient Electrochemical Sensor Based on Multi-Walled Carbon Nanotubes/Gold Nanocomposite for Detection of Dichlorvos Pesticide in Agricultural Food
}

\author{
Yi Chen", Kuo He, Fengmei Sun, Dong Wei, Hui Li \\ Key Laboratory of Analysis and Testing of Agricultural Products Food Quality and Safety in Hebei \\ Province, Hebei North University, Zhangjiakou 075000, Hebei, China \\ *E-mail:yiyi433@sina.com
}

doi: $10.20964 / 2021.03 .53$

Received: 25 November 2020 / Accepted: 7 January 2021 / Published: 31 January 2021

This study was conducted to prepare and electrochemical characterizeAu@MWCNTs nanocomposite modified GCE (Au@MWCNTs/GCE) as dichlorvos pesticides sensor in agriculture. Structure and morphology studies by SEM and XRD analyses showed the face-centered cubic structure of Au nanoparticles were formed and homogeneously distributed on network-like structure of MWCNTs which indicating to high porosity, large effective surface area and fast electron transfer rate of $\mathrm{Au} @$ MWCNTs/GCE. Cyclic voltammetry (CV) and differential pulse voltammetry (DPV) techniques were used to electrochemical characterization of Au@MWCNTs/GCE which shows the limit of detection and linear range of dichlorvos sensor were obtained $5 \mathrm{nM}$ and 1-120 $\mu \mathrm{M}$, respectively. Comparison of the prepared electrode with other similar reported sensors revealed a low detection limit and reasonable linear range for dichlorvos which is comparable with others carbon and gold nanostructured based sensors due to synergistic effects of Au nanoparticles and MWCNTs. Interference effects, stability and repeatability of dichlorvos sensors were investigated in the presence of different species. Analytical applicability of dichlorvos sensor was studied for prepared real samples of leaf lettuce which indicated acceptable values for recovery in the range of 90.75\%-97.50\% and relative standard deviation (RSD) in the range of 2.18\%-4.85\% which indicated Au@MWCNTs/GCE is reliable for the detection of dichlorvos in real samples.

Keywords: Dichlorvos; MWCNTs; Au@MWCNTs nanocomposite; Electrochemical sensor; Real samples

\section{FULL TEXT}

(C) 2021 The Authors. Published by ESG (www.electrochemsci.org). This article is an open access article distributed under the terms and conditions of the Creative Commons Attribution license (http://creativecommons.org/licenses/by/4.0/). 